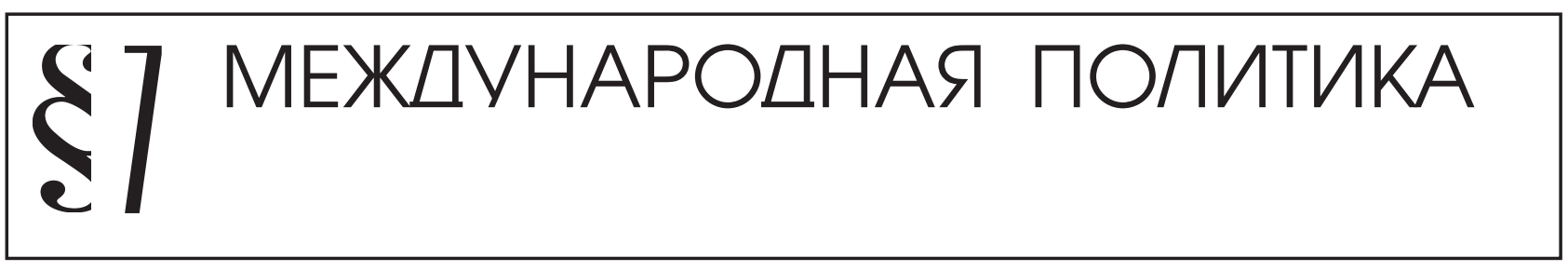

Ковалев Н.А.

\title{
ПОЛИТИЧЕСКАЯ АРХИТЕКТОНИКА СИСТЕМЫ МЕЖДУНАРОДНЫХ ОТНОШЕНИЙ: ФЕНОМЕН ПОЛЯРНОСТИ В СОВРЕМЕННОМ МИРЕ
}

\begin{abstract}
Аннотация: B статье анализируются некоторые тенденции развития системы международных отношений (СМО) в постбиполярную эпоху. Отмечается динамичность и противоречивость прочессов трансформации современного миропорядка, рост кризисных явлений в мировой политике, "турбулентность" современных международных отношений. Автором констатируется факт того, что геополитические схемы полярности СМО по-прежнему остаются актуальныли. Даётся характеристика термину "полярность" и приводится классификация традиционных и новых типов полярности СМО, разрабатываемых в современной политической науке (однополярность, биполярность, многополярность, бесполярность). Раскрываются основные особенности каждого из типов полярности, характеризующих возможное развитие международных отношений в XXI в. Делается вывод о том, что однополярная СМО в будущем невозможна ввиду усложнения и разнообразия современной картины мира. Вероятность формирования в ближайшем будущем полноценной новой биполярности, представленной США и другим субъектом международных отношений, пока остаётся под вопросом по причине отсутствия актора, обладающего соразмерным потенциалом. Утверждения о "бесполярной" сущности СМО, предполагающей крайнюю степень децентрализащии власти и управления в XХІ в., представляются преждевременными, поскольку формируюшийся многополярный мир характеризуется определённой иерархичностью, лидерством государств наличием норм и принципов функиионирования системы, возникновением и развитием разнообразных форматов взаимодействия, направленными на сохранение сбалансированности и устойчивости СМО.
\end{abstract}

Review: The author of the article analyzes some tendencies of development of the System of International Relations (SIR) during post-polarity epoch. The author empathizes dynamism and contradictory nature of transformation processes in the modern world order, the growth of crisis developments in the global policy and the 'roughness' of modern international relations. The author states the fact that geopolitical schemes of SIR polarity still do not lose their importance. The author offers a definition of the term 'polarity' and provides a classification of traditional and new types of SIR polarity developed in modern political sciences (unipolarity, bipolarity, polypolarity, polarityness). The author reveals the main peculiarities of each type of polarity and describes possible development of international relations in the XXI century. It has been concluded that unipolar SIR will be impossible in the future due to growing complexity and diversity of the world view. Formation of bipolar SIR as represented by the USA and another actor of international relations is still under the question because there is no actor which potentials would compare to the USA. It is too early for a polar-free SIR which assumes the extreme point of decentralization of power and government at the XXI century because a changing multipolar world has a particular hierarchy, leaders, standards of the system functioning and a whole variety of all kinds of communication formats aimed at keeping the balance and stability of the SIR.

Ключевые слова: Система международных отношений, полярность, однополярность, биполярность, многополярность, полицентричность, бесполярность, геополитика, баланс сил, глобализачия

Keywords: The system of international relations, polarity, unipolarity, bipolarity, multipolarity, polycentricity, polarityness, geopolitics, balance of forces, globalization. 
$\mathrm{C}$

истема международных отношений (далее - СМО) в последние несколько десятилетий качественно изменяется, эволюционирует, порождая новые и структурно разнообразные формы взаимодействия в современном мире. Специфика СMO в начале XXI века, по мнению многих исследователей, обусловливается также влиянием процессов глобализации - явления, основанного на взаимоотношениях и взаимозависимости различных подсистем и областей общественной жизни.

В условиях глубокой трансформации механизмов безопасности в современном мире и нарастания кризисных явлений в мировой политике (глобальный экономический кризис, «арабская весна», эскалация этнических конфликтов и пр.), вполне резонно согласиться с министром иностранных дел РФ С.В. Лавровым, отмечавшим, что «международные отношения вступили в зону турбулентности» ${ }^{1}$.

Современный мировой порядок в своей основе диалектичен и противоречив, что оказывает существенное влияние на разработку и развитие геополитических моделей функционирования международной системы. Несмотря на то, что после распада биполярной системы многие прежние предположения о будущем международных отношений устарели или были обновлены, схемы «полярности» СМО остаются актуальными и весьма популярными. Концепт полярности вышел из недр школы политического реализма в международных отношениях, остающегося одним из популярных направлений международных исследований и в XXI в.

В самом общем виде, полярность отражает «состояние системы, определяемое, преимущественно, через распределение силового потенциала между единицами системы. Соответственно, подобным распределением силы можно обозначить состояние системы как уни-, би-и многополярное, причём полярным необходимо считать не столько положение отдельных великих держав, а скорее их сферы влияния в широком смысле»².

1 Лавров, С.В. Международные отношения в зоне турбулентности - где точки опоры? // Дипломатический ежегодник - 2011 : Сборник статей. - М.: Аспект Пресс, 2012. - C. 13.

2 Albert, M. Hegemonie und Multipolarität unter den Bedingungen von Entgrenzung // Politik im 21. Jahrhundert:
Хотя, по сути, данное понятие более точно характеризует период развития международной системы во 2-й половине XX в., обусловленный конфронтацией и конкуренцией двух принципиально разных по своим параметрам политических систем, оно применяется и при характеристике других вариантов моделей функционирования международных отношений.

В данной статье автор ставит целью анализ традиционных и новых геополитических типов полярности СМО, разрабатываемых в политической науке, и оценку их соответствия реалиям XXI в. Можно выделить следующие типь полярности СМО:

1. Традиционная однополярность, или «плюралистическая» однополярность.

2. Новая биполярность.

3. Многополярный мир (полицентричность).

4. Эпоха «бесполярности».

\section{1. Традиционная однополярность, или «плюралистическая» однополярность.}

Окончательный распад СССР кардинально переконфигурировал международную систему, изменил принципы её функционирования, позволив сделать заключение о появлении «униполярности», представленной единственной оставшейся сверхдержавой США и ее западными союзниками ${ }^{3}$ и даже о своеобразном «конце истории», спрогнозированном американским исследователем Ф. Фукуямой и означавшем победу либеральной демократии над коммунизмом, господство западного образа жизни и распространение либеральных и демократических идеалов по всему миру.

Главенствующая роль западного мира в решении международных проблем в 90-е гг. обусловила стремление обосновать ключевые особенности сложившегося миропорядка:

1. Лидерство своеобразного «униполя» (термин принадлежит американскому исследователю А. Страусу), состоящего из развитых демо-

die Sammlung der Artikel. - Frankfurt am Main: SuhrkampVerlag, 2001. - S. 376.

${ }^{3}$ Krauthammer, Ch. The Unipolar Moment// Foreign Affairs. - 1990/1991. - Vol. 70. - № 1. - P. 23. 
кратических государств, обладающих наибольшим влиянием на международной арене.

2. Представления о том, что именно данная модель международных отношений является наиболее устойчивой и неконфликтогенной ${ }^{4}$.

3. Долговечность подобной модели, обусловленная невозможностью появления в будущем государств-конкурентов с подобным потенциалом по отношению к США 5 .

4. Второстепенная, дополняющая роль международных институтов и организаций ${ }^{6}$.

Однако, реалии 2000-х гг. существенным образом повлияли на эти представления. Следующие особенности развития СМО после 11 сентября 2001 года позволяют говорить об ослаблении глобального американского лидерства и, следовательно, об исчерпанности и упрощённости однополярной структуры международных отношений:

1. подъём новых и укрепление традиционных центров силы как на глобальном, так и на региональном уровнях международной системы, таких как Россия, Китай, ЕС, Индия, Бразилия и др..;

2. появление качественно новых акторов на политической арене (ТНО, НПО и др.), разнообразивших и усложнивших карту международных взаимодействий;

3. глобальный финансовый и, как следствие, экономический кризис;

4. рост насилия, конфликтогенности в разных регионах мира (Ближний Восток, Северная Африка, Центральная и Восточная Азия и пр.), обусловленный политико-экономическими, культурными, религиозными, национальными и прочими факторами;

5. угроза международного терроризма, затронувшего многие государства и нации и т.д.

Происходящие ныне трансформации СМО показывают неспособность США и Запада в целом

${ }^{4}$ Wohlforth, W.S. The Stability of a Unipolar World// International Security. - Summer 1999. - Vol. 24. - № 1. - P. 7-8.

5 Ibid., P. 8.

6 Krauthammer, Ch. The Unipolar Moment // Foreign Affairs. - 1990/1991. - Vol. 70. - № 1. - P. 25. в дальнейшем определять основные направления её развития, поддерживать статус глобального «полицейского» и укреплять мир и порядок на планете в одиночку. Излишне агрессивная политика Америки при президенте Буше-младшем серьёзно подорвала доверие к США со стороны других государств, а мировой кризис показал уязвимость их экономического положения, хотя США и останутся в будущем ведущей державой.

По мнению Бжезинского, главная задача Соединенных Штатов в ближайшем будущем - это «восстановление жизнеспособности идеи «Большого Запада» при одновременном продвижении ее и поддержании сложного равновесия на Востоке с учетом глобального усиления Китая» ${ }^{7}$, что предполагает планомерное укрепление связей с Европой и включение в «сообщество демократий» новых государств (Турция, Россия и др.), а также реализацию услуг посредника и регулятора в АТР при сопутствующем снижении роли силового компонента внешней политики США.

\section{2. Новая биполярность}

Масштабные трансформации СМО после окончания холодной войны, резкое увеличение влияния некоторых акторов на принимаемые в русле международной политики решения и их стремительное развитие, а также ослабление позиций США в мировой политике актуализировали дискуссии о возможности становления и формирования в будущем новой биполярной системы международных отношений.

В подобных теориях одно из мест традиционно отводится США как ведущей державе в современном мире. На роль второго субъекта данной модели мироустройства примериваются то ЕС, то Россия, однако, чаще всего (особенно в западной политологии), вторым потенциальном центром силы в последнее время объявляется Китай, опирающийся на мощный рост экономической и политической активности, достигнутый за последние десятилетия. Более того, большинством исследователей признаётся вполне реальным пе-

\footnotetext{
${ }^{7}$ Бжезинский, 3. Уравновесить Восток, обновить Запад // Россия в глобальной политике. 2012. № 1.

URL: $\quad$ http://www.globalaffairs.ru/number/UravnovesitVostok-obnovit-Zapad--15458 (дата обращения: 20.10.12013)
} 


\section{Политика и общество 11 (107) • 2013}

ренос международной активности с Запада на Восток, в Азию, где и будут приниматься ключевые решения в XXI в. ${ }^{8}$

Перспективы появления альтернативных центров силы с соразмерным потенциалом видятся исследователям, на данный момент, менее вероятными.

Предложение создать американо-китайскую дуополию для управления мировой экономикой выглядит как пример классического реализма во внешней политике. Оно опирается на концепцию баланса сил, исключая любые намеки на проблему ценностных ориентиров. Заполучив в лице Пекина прагматичного, гибкого и сильного партнера, США могли бы создать союз двух крупнейших экономик мира 9 .

В то же время, отмечается, что, несмотря на потенциальное экономическое лидерство Китая в будущем, противоречивость появления подобного союза («Большой двойки», G-2) из-за фактического отставания КНР от США в других сферах (военно-политической, в сфере геополитики, научно-технологической и пр.), внутренних экономических, социальных, экологических и прочих проблем, вынуждающих государство бросать на их решение абсолютное большинство сил и ресурсов, с одной стороны, и особенностей реализации самой внешней политики Китая, с другой, поскольку «в китайской системе внешнеполитических координат равноправные договоренности возможны лишь между игроками с равными потенциалами» ${ }^{10}$. Сpeди китайских исследователей международных отношений и политиков актуально мнение, что США, предлагая создать подобный стратегический союз, хотят таким образом разделить ответственность с Китаем в целях обеспечения безопасности в современном мире и вынудить его взять на себя риски, связанные с «издержками по защите американской гегемонии», поставить государство в более подчинённое положение в попытках сохранить глобальное лидерство Америки в будущем, а также получить возмож-

\footnotetext{
${ }^{8}$ Айкенберри, Д. Подъем Китая и будущее Запада // Россия в глобальной политике. -2008. - № 5. - С. 190.

9 Ломанов, А. Многополярная гегемония // Россия в глобальной политике. - 2008. - № 5. - С. 221.

${ }^{10}$ Там же. С. 223.
}

ность влиять на сложившуюся систему правления в $\mathrm{KHP}^{11}$.

Поэтому на официальном уровне предложения представителей американской элиты о возможности создания G-2 были отвергнуты китайским руководством, поставившим под сомнение легитимность такой «двойки», отметившим её упрощённость и односторонность воздействия на международную политику и экономику, что может подорвать нынешнюю многовекторную политику Китая на международной арене ${ }^{12}$ и непредсказуемо повлиять на уже сложившуюся систему альянсов и союзов на политической карте мира ${ }^{13}$.

\section{3. Многополярный мир (полицентричность)}

XXI век, по крайней мере в первом своем десятилетии, не стал новым «американским веком». Человечество, по оценкам многих ученых, вернулось к ситуации многополярности ${ }^{14}$, либо можно утверждать об этом как о «тенденции стратегического характера» ${ }^{15}$.

Формирующийся многополярный мир характеризуется появлением и проявлением новых тенденций, отличающих его от биполярности и однополярности:

Помимо традиционных игроков на международной арене (государств), действующих в уже сложившейся системе координат, увеличивается число новых центров, что снижает влияние государств на международную систему в целом ${ }^{16}$.

\footnotetext{
11 Там же. С. 226-227.

${ }^{12}$ ИноСМИ [Электронный ресурс]. Китай отвергает идею $\mathrm{G}-2$. -

URL: http://www.inosmi.ru/world/20090529/249494.html (дата обращения: 20.10.2013).

13 Ломанов, А. Многополярная гегемония // Россия в глобальной политике. - 2008. - № 5. - С. 221-222.

${ }^{14}$ Батюк, В. Постбиполярная ретроспектива мирового порядка // Международные процессы. 2010. № 2. URL: http://www.intertrends.ru/twenty-three/009.htm\#note20 (дата обращения: 20.10.2013).

15 Барановский, В.Г. Основные параметры современной системы международных отношений (Часть I) // Политические исследования. - 2012. - № 3. - С. 43.

${ }^{16}$ Гаджиев, К.С. К полицентрическому миропорядку // Политические исследования. - 2007. - № 4. - С. 12.
} 
Рост числа государств, оказывающих влияние на принятие политических решений на международной арене, и определённая иерархичность складывающейся структуры межгосударственных взаимодействий ${ }^{17}$. Ядро, высший уровень этой иерархии составляют примерно 10-15 государств (Россия, США, Китай, страны ЕС и др.).

Значительная роль в регулировании и управлении СМО различных международных институтов, блоков и альянсов как на глобальном (OOH), так и на региональном (НАТО, ЕС, ОАГ и др.), увеличение авторитета международного права, с одной стороны, а с другой, по мнению многих исследователей, остро чувствуется необходимость реформирования некоторых организаций, особенно в сфере безопасности, поскольку они создавались для урегулирования межгосударственных конфликтов и уже не отвечают реалиям современного мира, в котором основными угрозами считаются глобальные проблемы современности, терроризм, проблема распространения оружия массового поражения ${ }^{18}$ и т.д.

Усложнение структуры современного миропорядка и, как следствие, возникновение новых проблемных точек в международных отношениях приводит к попыткам конструирования и созданию иных разнообразных форматов сотрудничества: «двоек», «связок», «треугольников» (БРИКС, G-20, G-2, ШОС и др.).

Весомая роль процессов глобализации в мировой политике и экономике, укрепляющих взаимозависимость и взаимосвязанность современной СМО на всех уровнях и во всех подсистемах. В условиях складывающейся многополярности как никогда актуальны вопросы о роли традиционных акторов (государств), значения появляющихся транснациональных и иных негосударственных субъектов международных отношений, влияния на международную среду не только политических и экономических, но и культурных, информационных, технологических, религиозных, этнических и прочих факторов.

\footnotetext{
17 Барановский, В.Г. Основные параметры современной системы международных отношений (Часть III) // Политические исследования. - 2012. - № 5. - С. 150.

18 Батюк, В. Постбиполярная ретроспектива мирового порядка // Международные процессы. 2010. № 2. URL: http://www.intertrends.ru/twenty-three/009.htm\#note20 (дата обращения: 20.10.2013).
}

Безусловно, что вышеперечисленные особенности не исчерпывают сущность функционирования и развития многополярной модели СМО.

В рамках формирующейся полицентричности важнейшие, если не все, составляющие мирового сообщества взаимодействуют, сотрудничают и конфликтуют друг с другом, стремясь к реализации своих интересов. Отношения между многочисленными акторами чаще, чем раньше, устанавливаются по конкретным случаям и поэтому в большей мере подвержены изменениям. Такой миропорядок следует рассматривать не как нечто раз и навсегда данное. Это - открытая по всем направлениям и для всех влияний, постоянно изменяющаяся структура ${ }^{19}$.

\section{4. Эпоха «бесполярности»}

В 2000-х гг., ввиду усиления эффектов глобализации, транснационализации, ослабления старых акторов и появления новых, помимо уже сложившихся концептуальных идей касательно моделей полярности СМО, формируются представления о т.н. «бесполярной» сущности современных международных отношений, где бал правят «десятки акторов, способных оказывать различное влияние на положение дел в мире» ${ }^{20}$. Согласно американскому политологу П. Ханне, характер международных взаимоотношений и дипломатия после холодной войны символизируют о становлении своеобразной эпохи Средневековья, наступлении времени, когда политику творят «нарождающиеся державы, многонациональные корпорации, влиятельные семьи, гуманисты, религиозные радикалы, университеты, наемники» ${ }^{21}$ и прочие акторы.

Основа бытия современного миропорядка - укрепление глобальной взаимозависимости, ослабление традиционных субъектов международных отношений - государств и сложивших-

\footnotetext{
19 Гаджиев, К.С. К полицентрическому миропорядку // Политические исследования. - 2007. - № 4. - С. 18.

${ }^{20} X a a c$, Р. Эпоха бесполярного мира // Россия в глобальной политике. - 2008. - № 4. - С. 34.

${ }^{21}$ Ханна, П. Новое Средневековье // Россия в глобальной политике. 2012. № 2.

URL: $\quad$ http://www.globalaffairs.ru/number/NovoeSrednevekove-15530 (дата обращения: 20.10.2013).
} 


\section{Политика и общество 11 (107) • 2013}

ся после Второй Мировой войны институтов безопасности, взрывной рост численности различных центров и определённая непредсказуемость СМО.

Взаимозависимость проявляется в том факте, что глобальное управление, сфера принятия политических решений уже не изолированы от широкой общественности, приведя к тому, что «дипломатией ныне занимается любой маломальски значимый человек» ${ }^{22}$. Ширится и сфера ответственности, охватывающая уже не только традиционно сложившиеся области международных взаимодействий.

Кардинальное отличие эпохи «бесполярности» от традиционной модели многополярного мира заключается, по мнению американского исследователя Р. Хааса, в количественном росте новых центров влияния и их разнообразии ${ }^{23}$. Роль традиционных акторов международной политики - государств и международных институтов ослабнет, ибо уже сейчас они не способны противостоять «эре хаоса», в который ввергла мир глобализация ${ }^{24}$. Несмотря на то, что США останутся ведущей державой, обладающей огромным потенциалом, их влияние в мире и способность к глобальному управлению будут уменьшаться ${ }^{25}$, так же, как и ООН будет прилагать все усилия, чтобы сохранить систему устойчивой, но увеличить своё влияние будет не в состоянии ${ }^{26}$. Фактически, власть и управление будут децентрализованы.

По мнению исследователей, можно констатировать рост проблем управляемости международной системы, поскольку организовывать коллективные действия большого числа акторов на международной арене в современных условиях будет непросто. Кроме того, складывающийся ми-

\section{${ }^{22}$ Там же.}

${ }^{23} \mathrm{Xaаc,} \mathrm{Р.} \mathrm{Эпоха} \mathrm{бесполярного} \mathrm{мира} \mathrm{//} \mathrm{Россия} \mathrm{в} \mathrm{гло-}$ бальной политике. - 2008. - № 4. - С. 35.

${ }^{24}$ Ханна, П. Новое Средневековье // Россия в глобальной политике. 2012. № 2. URL: http://www.globalaffairs.ru/number/ Novoe-Srednevekove-15530 (дата обращения: 20.10.2013).

${ }^{25} \mathrm{Xaac,} \mathrm{Р.} \mathrm{Эпоха} \mathrm{бесполярного} \mathrm{мира} \mathrm{//} \mathrm{Россия} \mathrm{в} \mathrm{гло-}$ бальной политике. - 2008. - № 4. - С. 36.

${ }^{26}$ Ханна, П. Новое Средневековье // Россия в глобальной политике. 2012. № 2. URL: http://www.globalaffairs.ru/number/ Novoe-Srednevekove-15530 (дата обращения: 20.10.2013). ропорядок увеличивает число угроз основам безопасности в СМО, таких, как международный терроризм, распространение ядерного оружия ${ }^{27}$ и пр.

Согласно П. Ханне, в будущем нас ждёт эпоха «без правящих держав», «разделенный, раздробленный, неуправляемый, многополярный или бесполярный мир», где «Запад не заменит Востока, Китай не заменит Америки, а Тихий океан - Атлантики» ${ }^{28}$.

В условиях развития малоуправляемой, непредсказуемой системы международных отношений единственный выход из положения, который позволит, по мнению западных исследователей, обеспечивать безопасность в современном мире, - мультилатерализм (по Р. Хаасу), или «мегадипломатия» (по П. Ханне), означающие всемерное многостороннее сотрудничество самых разнообразных акторов, как традиционных (государства, глобальные институты), так и новых (ТНА, НПО и др.), с одной стороны, и реформирование институтов безопасности современного мира (OOH, G-8 и пр.), с другой, что должно способствовать развитию глобальной интеграции в будущем ${ }^{29}$.

Исходя из вышесказанного, можно утверждать, что процессы эволюции системы международных отношений после окончания холодной войны отличаются динамичностью и определённой непредсказуемостью развития, изменением базовых параметров СМО, появлением новых тенденций в развитии современного миропорядка.

Свершившимся фактом следует считать уход в прошлое периода однополярности системы международных отношений, оказавшейся неспособной адекватно реагировать на многие вызовы современного мира. Более того, ввиду сложности и разнообразия процессов, происходящих в мировой политике, необходимо упомянуть о невозможности формирования подобной модели СМО

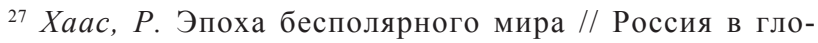
бальной политике. - 2008. - № 4. - С. 42.

${ }^{28}$ Ханна, П. Новое Средневековье // Россия в глобальной политике. 2012. № 2. URL: http://www.globalaffairs.ru/number/ Novoe-Srednevekove-15530 (дата обращения: 20.10.2013).

${ }^{29} X a a c$, Р. Эпоха бесполярного мира // Россия в глобальной политике. - 2008. - № 4. - С. 46-47. 
в будущем. Возможности США и их союзников всеразмерно влиять на международную систему объективно снижаются.

С другой стороны, вероятность появления полноценной новой биполярности остаётся под вопросом. В мире, на данный момент, нет государства-актора, обладающего соразмерным с США потенциалом в большинстве важнейших областей и сфер. ЕС, например, не обладает должной степенью единства в принятии политических решений в международных делах, в Европе, под влиянием последствий экономического кризиса, усиливаются тенденции суверенизации и автономизации, неравенство в решении ключевых вопросов. Россия, обладая все ещё внушительным (хотя и сократившимся) военно-политическим, геополитическим и дипломатическим потенциалом, не может похвастаться стабильным экономическим развитием и мощной внешнеэкономической активностью в других регионах мира, подобно Китаю.

Однако, и Китай, постепенно становящийся крупнейшим экономическим центром, в ближайшем будущем не сможет стать участником такой системы. Груз внутренних проблем (демографических, социальных и др.) и, как следствие, огромные затраты на поддержание стабильности государства, вынуждает Китай быть более осторожным и дальновидным во внешней политике, не ставя под угрозу сложившиеся взаимоотношения с другими акторами.

Представления же о «бесполярности» современного мироустройства, по мнению автора, хотя и представляют интерес, преждевременны. Безусловно, глобализация расширила круг субъектов на международной арене, однако, определённая иерархия, нормы и принципы в международной системе сохраняются, более того, сложность её регулирования способствует созданию новых механизмов решения проблем и угроз (G-20, БРИКС и др.). Возникающие транснациональные и негосударственные акторы, существенно повлияв на статус государств как традиционно главенствующих субъектов, всё же не будут обладать в ближайшем будущем потенциалом, способным оказывать решающее воздействие на международные отношения.

Скорее можно утверждать, что формирующийся ныне многополярный мир предполагает гибкое взаимодействие традиционных и новых субъектов международных отношений, не отрицая всё еще лидирующего положения государств как высшего звена международной системы в принятии ключевых решений, но уже с учётом новых тенденций и изменяющейся международной обстановки. Межгосударственные отношения по-прежнему строятся на основе баланса сил и интересов, создавая разнообразные форматы сотрудничества и взаимодействия, нацеленные на достижение сбалансированности и устойчивости СМO.

\section{Библиография:}

1. Лавров, С.В. Международные отношения в зоне турбулентности - где точки опоры? [Текст] / С.В. Лавров // Дипломатический ежегодник 2011 : Сборник статей. - М.: Аспект Пресс, 2012. - C. 13-22.

2. Батюк, В. Постбиполярная ретроспектива мирового порядка [Текст] // Международные процессы. 2010. № 2. URL: http://www.intertrends.ru/ twenty-three/009.htm\#note20

3. Барановский, В.Г. Основные параметры современной системы международных отношений (Часть I) [Текст] / В.Г Барановский // Политические исследования. - 2012. - № 3. - С. 36-44.

4. Барановский, В.Г. Основные параметры современной системы международных отношений (Часть III) [Текст] / В.Г Барановский // Политические исследования. - 2012. - № 5. - С. 148-158. 5.Гаджиев, К.С. К полицентрическому миропорядку [Текст] / К.С. Гаджиев // Политические исследования. - 2007. - № 4. - С. 8-23.

5. Хаac, Р. Эпоха бесполярного мира [Текст]/ Р. Хаас // Россия в глобальной политике. 2008. - № 4. - С. 34-48.

6. Айкенберри, Д. Подъем Китая и будущее Запада [Текст] / Д. Айкенберри // Россия в глобальной политике. -2008. - № 5. - С. 190-204.

7. Ломанов, А. Многополярная гегемония [Текст] / А. Ломанов // Россия в глобальной политике. 2008. - № 5. - С. 219-232.

8. Бжезинский, 3. Уравновесить Восток, обновить Запад [Текст] // Россия в глобальной политике. 2012. № 1. URL: http://www.globalaffairs.ru/number/Uravnovesit-Vostok-obnovit-Zapad--15458 


\section{Политика и общество 11 (107) 2013}

9. Ханна, П. Новое Средневековье [Текст] // Россия в глобальной политике. 2012. № 2. URL: http:// www.globalaffairs.ru/number/Novoe-Srednevekove- 15530

10. Krauthammer, Ch. The Unipolar Moment // Foreign Affairs. - 1990/1991. - Vol. 70. - № 1. - P. 23-33.

11. Wohlforth, W.S. The Stability of a Unipolar World // International Security. - Summer 1999. - Vol. 24. № 1. - P. 5-41.

12. Albert, M. Hegemonie und Multipolarität unter den Bedingungen von Entgrenzung / M. Albert // Politik im 21. Jahrhundert: die Sammlung der Artikel. - Frankfurt am Main: Suhrkamp-Verlag, 2001. S. 375-389.

13. ИноСМИ [Электронный ресурс]. Китай отвергает идею G-2. - URL: http://www.inosmi.ru/ world/20090529/249494.html

\section{References (transliteration):}

1. Lavrov, S.V. Mezhdunarodnye otnosheniya v zone turbulentnosti - gde tochki opory? [Tekst] / S.V. Lavrov // Diplomaticheskii ezhegodnik - 2011 : Sbornik statei. - M.: Aspekt Press, 2012. - S. 13-22.

2. Batyuk, V. Postbipolyarnaya retrospektiva mirovogo poryadka [Tekst] // Mezhdunarodnye protsessy. 2010. № 2. URL: http://www.intertrends.ru/twentythree/009.htm\#note20

3. Baranovskii, V.G. Osnovnye parametry sovremennoi sistemy mezhdunarodnykh otnoshenii (Chast' I) [Tekst] / V.G Baranovskii // Politicheskie issledovaniya. -2012 . - № 3. - S. 36-44.
4. Baranovskii, V.G. Osnovnye parametry sovremennoi sistemy mezhdunarodnykh otnoshenii (Chast' III) [Tekst] / V.G Baranovskii // Politicheskie issledovaniya. - 2012. - № 5. - S. 148-158. 5.Gadzhiev, K.S. K politsentricheskomu miroporyadku [Tekst] / K.S. Gadzhiev // Politicheskie issledovaniya. - 2007. - № 4. - S. 8-23.

5. Khaas, R. Epokha bespolyarnogo mira [Tekst] / R. Khaas // Rossiya v global'noi politike. - 2008. - № 4. - S. 34-48.

6. Aikenberri, D. Pod' 'em Kitaya i budushchee Zapada [Tekst] / D. Aikenberri // Rossiya v global'noi politike. -2008. - № 5. - S. 190-204.

7. Lomanov, A. Mnogopolyarnaya gegemoniya [Tekst] / A. Lomanov // Rossiya v global'noi politike. - 2008. - № 5. - S. 219-232.

8. Bzhezinskii, Z. Uravnovesit' Vostok, obnovit' Zapad [Tekst] // Rossiya v global'noi politike. 2012. № 1. URL: http://www.globalaffairs.ru/number/ Uravnovesit-Vostok-obnovit-Zapad--15458

9. Khanna, P. Novoe Srednevekov'e [Tekst] // Rossiya v global'noi politike. 2012. № 2. URL: http://www. globalaffairs.ru/number/Novoe-Srednevekove-15530

10. Krauthammer, Ch. The Unipolar Moment // Foreign Affairs. - 1990/1991. - Vol. 70. - № 1. - P. 23-33.

11. Wohlforth, W.S. The Stability of a Unipolar World // International Security. - Summer 1999. - Vol. 24. № 1. - P. 5-41.

12. Albert, M. Hegemonie und Multipolarität unter den Bedingungen von Entgrenzung / M. Albert // Politik im 21. Jahrhundert: die Sammlung der Artikel. - Frankfurt am Main: Suhrkamp-Verlag, 2001. S. 375-389. 